\title{
Article
}

\section{Poor Oral Health and its Neurological Consequences: Mechanisms of Porphyromonas gingivalis Involvement in Cognitive Dysfunction}

Olsen, Ingar and Singhrao, Simarjit Kaur

Available at http://clok.uclan.ac.uk/27830/

Olsen, Ingar and Singhrao, Simarjit Kaur ORCID: 0000-0001-9573-5963 (2019) Poor Oral Health and its Neurological Consequences: Mechanisms of Porphyromonas gingivalis Involvement in Cognitive Dysfunction. Current Oral Health Reports .

It is advisable to refer to the publisher's version if you intend to cite from the work. http://dx.doi.org/10.1007/s40496-019-0212-8

For more information about UCLan's research in this area go to http://www.uclan.ac.uk/researchgroups/ and search for <name of research Group>.

For information about Research generally at UCLan please go to http://www.uclan.ac.uk/research/

All outputs in CLoK are protected by Intellectual Property Rights law, including Copyright law. Copyright, IPR and Moral Rights for the works on this site are retained by the individual authors and/or other copyright owners. Terms and conditions for use of this material are defined in the policies page. 
2 Curr Oral Health Rep.

4 Mechanisms of Porphyromonas gingivalis Involvement in

\section{Cognitive Dysfunction}

7

\section{Ingar Olsen $^{1 *} \bullet$ Sim K. Singhrao ${ }^{2}$ \\ Corresponding author: Prof. Ingar Olsen \\ E-mail: ingar.olsen@odont.uio.no \\ Telephone: \\ $\underline{\text { ORCID ID (IO) and }}$ \\ (SKS): orcid.org/0000-0001-9573-5963}

${ }^{1}$ Department of Oral Biology, Faculty of Dentistry, University of Oslo, Oslo, Norway

${ }^{2}$ Dementia and Neurodegenerative Diseases Research Group, Faculty of Clinical and

Biomedical Sciences, School of Dentistry, University of Central Lancashire, Preston, UK

\section{Abstract}

Purpose of review: There is an increasing body of evidence from epidemiology and laboratory investigations on periodontal disease being a risk factor for dementia. In particular, Porphyromonas gingivalis infections in animal models suggest causal associations with Alzheimer's disease (AD). This review focusses on how $P$. gingivalis infections promote the incidence of functional loss in $\mathrm{AD}$.

Latest findings: The risk of the sporadic form of AD doubles when periodontitis persists for ten or more years. AD differs from other forms of dementia in that the clinical signs together with the presence of amyloid_beta $(\mathrm{A} \beta)$ plaques and neurofibrillary tangles must be present at autopsy. $P$. gingivalis oral infections in mice have demonstrated all of the characteristic pathological and clinical features of $\mathrm{AD}$ following infection upen their entry tof the brain. 
Summary: Multiple factors (inflammation, A $\beta$ oligomers, and bacterial factors) are likely to disrupt neuronal communication channels (synapses) as a plausible explanation for the functional loss.

\section{Abstract: 150 words}

Bulk of article: 3,640 words

Keywords Alzheimer's disease; Periodontitis; Interaction; P. gingivalis; Virulence factors

*Corresponding author:-Ingar Olsen, Department of Oral Biology, Faculty of Dentistry,

University of Oslo, P.O.B. 1052 Blindern, 0316 Oslo, Norway. E-mail address:

ingar.olsen@odont.uio.no 


\section{Introduction}

Longstanding periodontitis, formerly known as "chronic" periodontitis has an adverse effect on a number of complex human diseases associated with longstanding inflammation [1-3]. Recent research has linked poor oral hygiene to-other neurological conditions that manifest with dementia. Currently they include the sporadic form of Alzheimer's disease (AD), and the Lewy body Parkinson's disease (dementia) [4-6]. Amyloid-beta $(A \beta)$ plaques are central to all forms of dementia, but are more important to AD pathology. A significant body of literature considers the $\mathrm{A} \beta$ plaques of $\mathrm{AD}$ and the $\alpha$-synuclein of Lewy bodies to be antimicrobial peptides that combat infections of the brain [7-10]. This concept may provide vital clues to the occurrence of these neuropathological lesions.

\section{Porphyromonas gingivalis}

Porphyromonas gingivalis is found in the oral cavity (saliva) of all humans where it may or may not cause oral pathology, but is able to tolerate low concentrations of oxygen (microaearophilic). In addition, recent research has implicated $P$. gingivalis as the keystone pathogen of periodontitis, which is an inflammatory disease constituting complex dysbiotic microbial community residing below the gumline, within "pockets". P. gingivalis appears to translocate from the saliva to the subgingival location using neutrophils as "Trojan horses" in some individuals because clinical observations suggest that not everyone progresses to manifesting periodontal disease.

The mouth harbours a microbiome, which essentially is a reservoir of health promoting microbes until their balance changes to more pathogenic forms. The fact that $P$. gingivalis can act as a commensal,and provides us with an opportunity to discuss the role of its source of Porphyromonas gingivalis its primary oral source to its access of the brain in relation to cognitive dysfunction. This is not only because-AD is a prime example of a dementing neurological disease but also forthat has a plausible the established association with $\Theta f$. gingivalis with both the $\mathrm{AD}$ brain $[11,12]$. and periodentitis as a keystone bacterium [12]. In addition, This is strengthened by the development of models for periodontal infection and $\mathrm{AD}$ in mice $P$. gingivalis infection to the brain directly from its primary oral niche [13] where it has been demonstrated to ean-reproduce the cardinal hallmark pathology inclusive of $\mathrm{A} \beta$ plaques, phosphotau [14], and cognitive function in experimental mice-[15-17]. 


\section{Alzheimer's disease}

$\mathrm{AD}$ is end of life stage and the most common example of dementia. The cardinal clinical signs are cognitive decline with deterioration in memory. The hHippocampus is the region of the brain where memory is processed and the functional loss has been associated with the death of neurons in specific regions of the brain related to memory. AD has a long preclinical phase (20 years) with the duration of suffering lasting on average for 8-10 years and longer [18]. At the preclinical stage of the illness, the individual may not seek medical help. Usually a family member or the caregiverf of the person with declining cognition and memory may voice their concern to a health care professional. This may be their general medical practitioner (GP) or a health care professional (district nurse). The first stage in exploring this health complaint is for the caregiverr to take the person (with suspected dementia signs) to his/her GP. The GP will then refer the person on to a memory service to establish a more formal clinical diagnosis, and initiate treatment and support. The final diagnosis of AD rests with both the clinical history together with the demonstration of the neuropathological occurrence of $A \beta$ plaques and hyperphosphorylated tau protein binding to neurofibrillary tangles in a characteristic pattern and distribution in the specific regions of the brain. AD neuropathology can co-exist with other neurological and/or vascular pathologies because it is not an isolated disease.

\section{Plausible cause of Alzheimer's disease and Lewy-body dementia}

The cause of the sporadic forms of the neurological diseases under discussion (AD and Parkinson's disease with Lewy bodies) remains unclear. However, amongst others, the risk factors include ageing and inheritance of the apolipoprotein E gene allele 4 (APOE $\epsilon 4)$ [19, 20]. The $A P O E \in 4$ susceptibility gene links with environmental risk factors that include the host's dysbiotic oral microbiome [21]. P. gingivalis infections of the brain in laboratory mice induced with periodontitis demonstrate excessive oxidative stress and inflammation [13-15, 22].

Lewy bodies are intra-neuronal cytoplasmic inclusions composed of synuclein and other proteins lying within the pigmented neurons of the substantia nigra, limbic and the cerebral cortex regions of the brain. The clinical symptoms of Parkinson's disease in its purest form are tremor, immobility and rigidity of muscles. However, cognitive deficit occurs when Parkinson's disease co-exists with dementia (Lewy body Parkinsonian dementia), see comment above related to mixed pathologies. Epidemiological investigations $[4,5]$ in a 
Taiwanese population have linked this to periodontal disease. As mentioned earlier, the $A \beta$ protein of $\mathrm{AD}$ plaques and the $\alpha$-synuclein within Lewy bodies are a form of broad-spectrum antimicrobial peptides, released following infection, including that caused by the periodontal pathogen $P$. gingivalis [7-10, 14]. If A $\beta$ and $\alpha$-synuclein represent the host's response to a previous infection, it follows that these neurodegenerative diseases have causative associations with microbes during their development. This has given rise to the antimicrobial protection hypothesis [23] linking infection as a plausible trigger for the sporadic form of AD. If this theory becomes widely accepted, then explaining the existing oxidative stress, the activated complement, the longstanding inflammation and the defects in the blood-brain barrier (BBB) would be easy in the context of $P$. gingivalis infection [13, 22, 24]. All of the above-mentioned signaling cascades and others (not included here), would enhance the role of $\mathrm{A} \beta$ as an antimicrobial peptide in killing the elusive invader(s) and/or the little understood brain's own microbiome converting to a pathobiome. In addition, the elderly are unlikely to be immuno-privileged because the BBB defects in the 70+ year's age group are associated with more rapid cognitive decline [25] and could have implications for pathogen entry.

\section{Plausible cause of cognitive deficit}

What actually causes the cognitive deficit during dementia onset is unclear, because the individual examples of dementia such as $\mathrm{AD}$ are seldom pure. However, the amyloid cascade hypothesis originally focused on $A \beta$ deposits as a possible cause [26]. Subsequent immunological therapy to remove $\mathrm{A} \beta$ plaques from the brains of $\mathrm{AD}$ patients disproved the notion that insoluble $\mathrm{A} \beta$ deposits contribute to cognitive dysfunction [27]. Prior to the amyloid hypothesis, the synaptic loss hypothesis of Terry et al. [28] and Masliah et al. [29] originated from the fact that specific neuronal loss may be due to synaptic loss. The revised version of the amyloid cascade hypothesis has incorporated soluble oligomeric $A \beta$ in the synaptotoxicity and cognitive impairment theory [30]. It is possible that there is close interplay between the mechanisms underlying these three hypotheses. After all, it is highly plausible that microbial debris, inflammatory mediators, oligomeric $\mathrm{A} \beta$, smaller tau peptides released by gingipains, and pathogen activated inflammasomes [31], can all act to disrupt synapses and result in cognitive deficit.

\section{Relationship between periodontitis and AD}


The idea of dementia being a risk factor for periodontitis is undisputable, but then one would expect all demented individuals to have periodontitis by the time of death. Literature suggests the formerly known "chronic" periodontitis has a clearer relationship with a subgroup of AD cases [32-36]. Significant progress will only be made to find the actual direction of this relationship, once we better understand the parameters that should be included and/or excluded from the investigation in case control and/or cohort studies. For example, we now understand that periodontitis only becomes a risk factor for AD development some 10 years after it is diagnosed $[37,38]$. This would imply that studies conducted in less than 10 -year cohort analysis would provide inconclusive results [39]. One suggested risk of developing AD is having fewer remaining teeth (loss of up to 9 teeth) in early to mid-life due to periodontitis $[30,40]$, resulting from longstanding poor oral hygiene. For a more comprehensive discussion on the direction of the relationship between oral health and risk of developing $\mathrm{AD}$, see Daly et al. [41]. There is agreement that periodontitis doubles the risk for developing late onset AD with an odds ratio of 2.2 (95\% CI 1.1, 4.5) 10 years after its initial diagnosis [37, 38]. An interventional study on the periodontal treatment in $\mathrm{AD}$ patients [42] indicated a plausible causal relationship in demented individuals. It is suggested that patients with early stage dementia (at the time ofpoint when they visiting the memory clinic for initial diagnosis) show worsening oral hygiene [43], implying that dementia may be the risk factor for periodontal disease in this group of patients. It is also suggested that if dental intervention is provided at the early stage of dementia onset, it would delay the speed of cognitive deterioration. Early intervention is important and memory clinics should consider taking it on at the time the initial diagnosis [43]. However, to confirm the direction of the relationship, more studies with larger cohorts are needed in the "at risk" subpopulation of individuals whose periodontitis coexists with AD cases. In addition, future interventional studies should include participants who suffer from periodontitis approaching the risk age for dementia (pre 65-year age) for maximal impact on delaying the onset of $\mathrm{AD}$.

\section{Relationship of $P$. gingivalis with AD development}

As mentioned, $P$. gingivalis is considered a keystone pathogen in periodontitis [12] and it is adept at manipulating the sub-gingival microbiome and the host's immune system [44-49]. $P$. gingivalis is an intracellular pathogen that has been used to develop $\mathrm{AD}$ via periodontal infection in mice [13, 14]. The infection periodontal model of Ilievski et al. [14] produced the $\mathrm{AD}$ defining hallmark lesions in the mouse brains $(\mathrm{A} \beta$ and phosphotau neurofibrillary 
tangles), a finding reproduced in mice by Dominy et al. [50]. Since the Ilievski and the Dominy models were of wild type mice, there is a high probability that $\mathrm{A} \beta$ was cleaved from its precursor protein into various oligomer sizes following oxidative stress initiated by $P$. gingivalis, which in turn activated cathepsin B within the endo/lysosomes [22, 51]. This intracellular processing of $A \beta$ agrees with the earlier report of $\mathrm{Wu}$ et al. [15] showing, that metabolic processing of the amyloid precursor protein after $P$. gingivalis lipopolysaccharide (LPS) was administered into cathepsin B sufficient mice. Other studies in which either $P$. gingivalis or its LPS was introduced, supported the development of the AD-like clinical phenotype $[15-17,52]$ resulting in impaired spatial learning and memory. All of these investigations support a causal relationship of periodontitis with the development of AD.

\section{Mechanisms of cognitive deficit by $P$. gingivalis infection}

\section{Soluble oligomeric $A \beta$ and $B B B$ defects}

In line with Dominy et al. [50] confirming $P$. gingivalis genetic footprints (DNA) in the AD brains, in vivo infection models of periodontitis are recapitulating hallmark proteins and the emerging phenotype is supporting cognitive deficit [14-17, 52]. $P$. gingivalis produces two types of cysteine proteases (gingipains). They are the lysine specific Kgp and the arginine specific RgpA and RgpB gingipains [53]. A novel finding described by Dominy et al. [50] is the capacity of these proteases to hydrolyse the biochemical structure of the protein tau, and this opens up future avenues for research.

Gingipains activity has the potential to erode endothelial tight junction proteins [24] as supported by the $P$. gingivalis/host interactome study [54]. Cognitive deterioration due to BBB defects in the human elderly individuals are also documented [25] and this may yet be another contributory factor in mice models displaying AD-like clinical phenotype. In addition, if the soluble form of the olgomeric $A \beta$ can interfere with synapses and contribute to cognitive deficit, as proposed by Cline et al. [30]. Then $P$. gingivalis oral infection can also contribute to this protein following its entry into the brain $[14,50]$.

\section{Inflammation and inflammatory mediators in general}

Numerous studies have shown that LPS from Gram negative bacteria either administered directly into the peritoneum or the brain, induce neuroinflammation in the form of glial cell activation [55] and when measured, the inflammatory response is accompanied by learning and memory impairment $[56,57]$ as a result of IL- $1 \beta$ secretion following peripheral challenge with LPS [58]. This is in agreement with the Wu et al. [15] hypothesis that systemic 
administration of $P$. gingivalis LPS leads to cognitive deficit following A $\beta$ liberation in an IL$1 \beta$ receptor dependent pathway on neurons, (also see [21]). IL-1 $\beta$ cytokine is implicated in synaptic loss $[59,60]$ and with reduced long-term potentiation, which is a unit of memory [59], supporting the role of this cytokine in deteriorating cognition.

\section{$P$. gingivalis, complement, and immune dysbiosis}

Gingipains are virulence factors of great importance to the immune subversion activity of $P$. gingivalis [53]. In the context of the complement cascade, these proteases play a major role. $P$. gingivalis oral infection of apolipoprotein $\mathrm{E}^{-/-}$mice demonstrated complement activation in their brains [13]. Activation of complement does take place in $\mathrm{AD}$ brains, where $\mathrm{A} \beta$ plaques are the suggested trigger [61]. If, according to the novel hypothesis of Allen [62] that $A \beta$ senile plaques are miniature foci of bacterial biofilms, and that the antimicrobial protection theory of Moir et al. [23] supporting the $A \beta$ antimicrobial peptide idea then the downstream immune activity triggering complement activation in $\mathrm{AD}$ brains does fit. Inappropriately activated complement compromises the function of healthy neurons, because of their inadequate shielding from protective proteins that rescue them from the non-specific mode of activity of this powerful innate immune signaling cascade [63]. During complement activation, release of several small proteins (opsonins) takes place, which then opsonize to neurons [13]. Depending on the site of opsonin binding to the neuron, (e.g. at the synaptic cleft), there remains a potential to disrupt the path of neuronal communication and give way to cognitive dysfunction. In addition, the continuation of this cyclic cascade will generate more cytokines and contribute to cognitive deficit (see above).

$P$. gingivalis infection continues to cleave complement components (C1-C5) through its gingipains activity, and prevents both deposition of $\mathrm{C} 3 \mathrm{~b}$ on the bacterial surface and capture of the $\mathrm{C} 4 \mathrm{~b}$ binding protein [64-68]. By hijacking the complement regulator $\mathrm{C} 4 \mathrm{bp}$ on the bacterial surface, $P$. gingivalis prevents assembly of the membrane attack complex and acquires the ability to regulate $\mathrm{C} 3$ convertase [66]. Accordingly, the gingipains do not only destroy complement through proteolytic degradation, but they also inhibit activation of complement by binding to the complement inhibitor C4bp [66]. This inhibits complement action and results in a local accumulation of the anaphylatoxin C5a [69]. P. gingivalis also exerts C5 convertase-like enzymatic activity and exploits complement-Toll like receptor (TLR) crosstalk to subvert host defenses and thus escape elimination from the host [45]. Zhang et al. [52] recently demonstrated that the mechanism by which $P$. gingivalis impaired 
spatial learning and memory is via TLR crosstalk because inhibiting this pathway rescued memory in their infection mouse model.

As an analogy to TLR signaling, our in house data clearly showed that CD14, an LPS binding receptor, expressed on healthy IMR32 neurons (also participates in TLR signaling) was completely or partially removed following exposure to endo/exotoxins from $P$. gingivalis ATCC $33277^{\mathrm{T}}$ and W50, respectively (see Figure 1). Such mechanisms lead to defective immune surveillance because of their influence in remodeling the periodontal microbiota into a dysbiotic state. $P$. gingivalis can also reduce the antibacterial and proinflammatory activity of C5a by deiminating its C-terminal arginine residues [70]. Degradation of complement proteins probably allows colonization and proliferation of bacteria possessing higher sensitivity towards complement killing than found in $P$. gingivalis itself [47]. Thus, $P$. gingivalis may support survival of the entire biofilm community by helping bystander bacteria evade complement mediated killing [46], whilst neurons survive with compromised function. These activities have consequences for the developing neuropathology. Thus, the neuropathology and the clinical functional loss together, constitute the AD diagnosis. $P$. gingivalis infection under laboratory conditions are supporting both of these possibilities [13$17,22,24,52]$.

\section{Bacterial factors disrupting synapses}

Our in-house in vitro studies in which IMR32 (neuroblastoma-derived) neurons challenged with $P$. gingivalis virulence factors (containing LPS and gingipains) indicated considerable alterations in their actin cytoskeletal filaments following their detection with fluoresceinphalloidin dye. The LPS binding to cell surface membranes caused blebbing [11], whilst the protease caused the cells to withdraw their processes and round up (see Figure 2). In summary, the structural alteration of the IMR32 neurons, in vitro, could provide the basis for the failure of communication between neighboring cells. In addition, excess bacterial/inflammatory mediators possibly trap between micro spaces of opposing (pre-post) synapses (synaptic clefts) or adversely affect synaptosomes during their neurotransmitter release contributing to cognitive loss. These areas are open to future investigations in relation to memery. Infection of microglia with $P$. gingivalis in mice has promoted cell migration and an inflammatory response through gingipain-mediated activation of protease-activated receptor-2 [71]. We need to clarify if and how infectious episodes impair memory at the synaptosomal level, rather than at the synaptic cleft level. Such information may refine our 
understanding at an earlier stage of deteriorating cognition albeit at the neurotransmitter release and its uptake levels.

\section{Dysbiosis of immune defense by alternative means}

miRNA has a role in the virulence of $P$. gingivalis, contributing to modulation of host-cell immune responses in a manner that promotes bacterial survival, and progressively reduces the host's protective function [49]. Some miRNAs are even associated with $P$. gingivalis itself [72], while others (miRNA-128, miRNA-146, miRNA-203, and miRNA-584) are host derived for inflammation. Bacterium-associated miRNAs are likely to influence the innate immune response against $P$. gingivalis, whereas LPS from this bacterium may affect the level of the host's miRNA-mRNA interactions. These miRNA-dependent effects may supplement other forms of deception exerted by $P$. gingivalis thus subverting innate and adaptive immune responses possibly by altering gene function $[54,69]$.

\section{$P$. gingivalis and tau protein phosphorylation}

As mentioned earlier, Ilievski et al. [14] demonstrated that $P$. gingivalis infection can lead to tau phosphorylation and neurofibrillary tangle formation in mice. The neurons that develop these hallmark lesions in the human AD brain are cells with compromised function, and the structural change in the nerve cell soma and axons, the later disrupting their connectivity. The effect of gingipains on the integrity of actin filaments seen with IMR32 neurons (Figure 2) may be analogous to the neurofibrillary tangle bearing neurons in AD. This structural change is likely to be detrimental to their communications with other brain cells resulting in deteriorated cognition.

Previously, we have discussed outer membrane vesicles (microbullets) from $P$. gingivalis [73] playing a role in AD development. $P$. gingivalis cultures produce them in vast numbers, suggesting they constitute the main superhighway of communication with other bacteria in the biofilm [74]. Since they carry additional arsenals of weapons to manipulate their entry into disparate organs, disrupt actin structures, erode epithelial junctional proteins, hijack phagocytosis, destroy tissues, and affect complement related genes, they may also be responsible for transducing proinflammatory signaling cascades that ultimately lead to disease defining lesion development and cognitive decline, typical of clinical AD.

Ilievski et al. [14] demonstrated a chronic infection with live P. gingivalis strain W83 for 22 weeks with both the hallmark lesions (A $\beta$ and NFTs) that characterize AD with tau
Commented [SKS < oD1]: I think this is the sentence asked to be clarified?, needs addressing 
protein phosphorylation at the serine396 (ser396) residue. This generated a new concept that an oral infective focus in neurological diseases may result in dementia. Up until now, abnormally phosphorylated tau protein has not featured negatively in the pathophysiology of periodontal disease per se. However, Adamowicz et al. [75] implicated the role of glycogen synthase kinase 3 (GSK-3) in bacterial-induced periodontitis because its inhibition rescued bone loss. Thus, GSK-3 may be influencing phosphorylation of brain tau via immune responses mediated by $P$. gingivalis, in the Ilievski et al. [14] study. GSK-3 $\beta$ appears to mediate proinflammatory cytokine production during bacterial infections because inhibition of GSK-3 $\beta$ leads to an innate hypo-reactivity to oral pathogens [76]. Macrophages treated with LPS, in vitro suggest that GSK-3 $\beta$ stimulates interferon- $\beta$ (IFN- $\beta$ ) production via c-Jun thus activating a transcription factor (ATF)-2-dependent mechanism [76]. GSK-3 $\beta$ also negatively regulates production of the endogenous IL-1 $\beta$ antagonist, IL-1R, via its ability to regulate the MAPK and ERK 1/2 in LPSstimulated innate immune cells. There is no doubt that further research will widen investigation of these pathways for more direct causal links with oral disease and dementing diseases with cognitive deterioration.

The Dominy et al. [50] publication has provided a stronger argument for the role of pathogenic tau in $\mathrm{AD}$ development. In their in vitro neuronal culture system, Dominy et al. [50] demonstrate that tau is a substrate for gingipains and show a low molecular weight band corresponding to a novel tau peptide. Further research will establish if it is neurotoxic or not.

\section{$P$. gingivalis and lymphocytes}

It is possible that $\mathrm{T}$ cell entry into the $\mathrm{AD}$ brain is restricted and this somehow influences ineffective clearance of the $A \beta$ by macrophages and the resident microglia. Baek et al. [77] found that Treg cells (subpopulation of T cells) had an effect on cognitive function by decreasing $\mathrm{A} \beta$ deposition and inflammatory cytokine secretion in a 3xTg-AD mice model. In contrast, depletion of Tregs increased the onset of cognitive deficit, accelerated the amount of the $\mathrm{A} \beta$ burden, enhanced microglia/macrophage responses and decreased glucose metabolism in 3xTg-AD mice. In patients with atherosclerosis, the Treg population was reduced if they harbored type II fimA of $P$. gingivalis compared to those with other types of fimbriae [78]. Therefore, $P$. gingivalis type II fimA could be associated with dysregulation of Tregs in extraoral lesions. Severe immunosuppression seems to favor not only colonization with varying serotypes of periodontopathogenic bacteria, but also with species not commonly found in the subgingival microbiota [79]. In the brain, this may contribute to the 
establishment of a multi species microbiota, previously reported in AD patients [80]. In addition, accumulation of insoluble and toxic $\mathrm{A} \beta 42$ has detrimental effect on the neighboring neurons and their connections, which may have further implications for neurodegeneration and related cognitive loss.

\section{Conclusions}

Dominy et al. [50] have recently provided robust data linking the main pathogen $(P$. gingivalis) of periodontitis with the cause of $\mathrm{AD}$. This bacterium appears to migrate from the mouth to the brain of some individuals as they age and a significant proportion of subjects who go onto developing AD. This further highlights the possibility that AD has a microbial infection origin. Ilievski et al. [14] provide evidence for $P$. gingivalis infection having causal associations by reproducing the hallmark lesions. Four independent studies carried out in mice infected with $P$. gingivalis provide causal links through impaired learning and memory. The suggested mechanism is related to the TLR crosstalk and this may have relevance to the inflammasome formation with the resulting cytokines (mature IL-1 $\beta$ ) being linked to memory disturbances.

These studies reinforce the advice that oral hygiene is important in keeping pathogens low and encouraging greater diversity of commensals (health promoting bacteria). This provides a healthy microbiome and better general health. Health authorities need to heed this warning and take research based evidence seriously. The UK NHS England provides a recommendable oral health toolkit for the elderly to maintain better oral hygiene with the aim of delaying/preventing AD.

Conflict of Interest The authors declare no conflict of interest.

\section{Human and Animal Rights and Informed Consent}

Not applicable. This is a review of literature and does not rely on freshly obtained data from human and/or animal studies. Figures are from our in-house cell culture studies that are exempt from ethical issues.

\section{References}

Papers of particular interest, published recently, have been highlighted as: 
*Of importance

**Of major importance.

***Of significant importance

1. Olsen I. From the Acta Prize Lecture 2014: the periodontal-systemic connection seen from a microbiological standpoint. Acta Odontol Scand. 2015; 73(8): 563-8. DOI: 10.3109/00016357.2015.1007480.

2. Olsen I, Singhrao SK. Can oral infection be a risk factor for Alzheimer's disease? J Oral Microbiol. 2015; 7: 29143. DOI: 10.3402/jom.v7.29143.

3. Olsen I, Singhrao SK, Potempa J. Citrullination as a plausible link to periodontitis, rheumatoid arthritis, atherosclerosis and Alzheimer's disease. J. Oral Microbiol. 2018; 10(1):1487742. DOI: 10.1080/20002297.2018.1487742.

4. **Chen $\mathrm{CK}, \mathrm{Wu}$ YT, Chang YC. Periodontal inflammatory disease is associated with the risk of Parkinson's disease: a population-based retrospective matched-cohort study. PeerJ. 2017; 5:e3647. DOI: 10.7717/peerj.3647. Reducing periodontitis may modify the risk of developing Parkinson's disease.

5. **Chen CK, Huang JY, Wu YT, Chang YC. Dental scaling decreases the risk of Parkinson's disease: A nationwide population-based nested case-control study. Int J Environ Res Public Health. 2018; 15(8). pii: E1587. DOI: 10.3390/ijerph15081587.

First study to show that patients without periodontitis who received dental scaling over 5 consecutive years had a significantly lower risk of developing Parkinson's disease.

6. **Pang S, Li J, Zhang Y, Chen J. Meta-analysis of the relationship between the APOE gene and the onset of Parkinson's disease dementia. Parkinsons Dis. 2018; 2018: 9497147. DOI: 10.1155/2018/9497147. APOE genotypes, $\boldsymbol{\varepsilon} 3 / \mathbf{4}$ and $\boldsymbol{\varepsilon 4 / 4}$ may be risk factors for Parkinson's disease dementia.

7. **Soscia SJ, Kirby JE, Washicosky KJ, Tucker SM, Ingelsson M, Hyman B, et al. The Alzheimer's disease-associated amyloid beta-protein is an antimicrobial peptide. PLoS One. 2010; 5(3): e9505. DOI: 10.1371/journal.pone.0009505. Abeta is a hitherto unrecognized antimicrobial peptide that may normally act in the innate immune system.

8. Kumar DK, Choi SH, Washicosky KJ, Eimer WA, Tucker S, Ghofrani J, et al. Amyloid- $\beta$ peptide protects against microbial infection in mouse and worm models of 
Alzheimer's disease. Sci Transl Med. 2016; 8(340): 340ra72. DOI: 10.1126/scitranslmed.aaf1059.

9. **Park SC, Moon JC, Shin SY, Son H, Jung YJ, Kim NH, et al. Functional characterization of alpha-synuclein protein with antimicrobial activity. Biochem Biophys Res Commun. 2016; 478(2): 924-8. DOI: 10.1016/j.bbrc.2016.08.052. Alpha-synuclein appears to be a natural antimicrobial peptide in addition to having a role in neutransmitter release.

10. Eimer WA, Vijaya Kumar DK, Navalpur Shanmugam NK, Rodriguez AS, Mitchell

$\mathrm{T}$, Washicosky KJ, et al. Alzheimer's disease-associated $\beta$-Amyloid is rapidly seeded by Herpesviridae to protect against brain infection. Neuron. 2018; 99(1): 56-63.e3. DOI: 10.1016/j.neuron.2018.06.030.

11. **Poole S, Singhrao SK, Kesavalu L, Curtis MA, Crean S. Determining the presence of periodontopathic virulence factors in short-term postmortem Alzheimer's disease brain tissue. J Alzheimers Dis. 2013; 36(4): 665-77. DOI: 10.3233/JAD-121918. The original study confirmed that $\boldsymbol{P}$. gingivalis lipopolysaccharide reaches the Alzheimer disease brain.

12. *Hajishengallis G, Darveau RP, Curtis MA. The keystone-pathogen hypothesis. Nat Rev Microbiol. 2012; 10(10): 717-25. DOI: 10.1038/nrmicro2873. The keystonepathogen hypothesis holds that certain low-abundance microbial pathogens can orchestrate inflammatory disease by remodelling a normally benign microbiota into a dysbiotic one.

13. ***Poole S, Singhrao SK, Chukkapalli S, Rivera M, Velsko I, Kesavalu L, et al. Active invasion of Porphyromonas gingivalis and infection-induced complement activation in $\mathrm{ApoE}^{-/-}$mice brains. J Alzheimers Dis. 2015; 43(1): 67-80. DOI: 10.3233/JAD-140315. P . gingivalis was able to access the ApoE $\mathbf{E}^{-/-}$mice brain contributing to complement activation by bystander neuronal injury.

14. ***Ilievski V, Zuchowska PK, Green SJ, Toth PT, Ragozzino ME, Le K, et al. Chronic oral application of a periodontal pathogen results in brain inflammation, neurodegeneration and amyloid beta production in wild type mice. PLoS One. 2018; 13(10): e0204941. DOI: 10.1371/journal.pone.0204941. First study to show neurodegeneration and formation of extracellular Aß42 and phosphotau bound to neurofibrillary tangles in young adult wild type mice after repeated application of $P$. gingivalis. 
15. ***Wu Z, Ni J, Liu Y, Teeling JL, Takayama F, Collcutt A, et al. Cathepsin B plays a critical role in inducing Alzheimer's disease-like phenotypes following chronic systemic exposure to lipopolysaccharide from Porphyromonas gingivalis in mice. Brain Behav Immun. 2017; 65: 350-61. DOI: 10.1016/j.bbi.2017.06.002. Chronic systemic exposure to PgLPS induced AD-like phenotypes, including microgliamediated neuroinflammation, intracellular $\mathrm{A} \beta$ accumulation in neurons and impairment of the learning and memory functions in the middle-aged mice in a CatB-dependent manner. Linked IL-1 $\beta$ involvement in memory deterioration.

16. **Ishida N, Ishihara Y, Ishida K, Tada H, Funaki-Kato Y, Hagiwara M, et al. Periodontitis induced by bacterial infection exacerbates features of Alzheimer's disease in transgenic mice. NPJ Aging Mech Dis. 2017; 3: 15. DOI: 10.1038/s41514017-0015-x. Periodontitis caused by $\boldsymbol{P}$. gingivalis may exacerbate brain A $\beta$ deposition, leading to increased cognitive impairments, by a mechanism that involves triggering brain inflammation.

17. **Ding Y, Ren J, Yu H, Yu W, Zhou Y. Porphyromonas gingivalis, a periodontitis causing bacterium, induces memory impairment and age-dependent neuroinflammation in mice. Immun Ageing. 2018; 15: 6. DOI: 10.1186/s12979-0170110-7. The learning and memory abilities of the middle-aged mice infected with $P$. gingivalis were impaired.

18. Masters CL, Bateman R, Blennow K, Rowe CC, Sperling RA, Cummings JL. Alzheimer's disease. Nat Rev Dis Primers. 2015; 1: 15056. DOI: 10.1038/nrdp.2015.56.

19. **Singhrao SK, Harding A, Chukkapalli S, Olsen I, Kesavalu L, Crean S. Apolipoprotein E related co-morbidities and Alzheimer's disease. J Alzheimers Dis. 2016; 51(4): 935-48. DOI: 10.3233/JAD150690. The apolipoprotein $\mathbf{E}$ gene allele 4 is the plausible commonality for the etiology of co-morbidities that eventually result from periodontal diseases and ultimately progress to mixed pathologies and dementia.

20. Li J, Luo J, Liu L, Fu H, Tang L. The genetic association between apolipoprotein E gene polymorphism and Parkinson disease: A meta-analysis of 47 studies. Medicine (Baltimore). 2018; 97(43): e12884. DOI: 10.1097/MD.0000000000012884.

21. *Singhrao SK, Olsen I. Assessing the role of Porphyromonas gingivalis in periodontitis to determine a causative relationship with Alzheimer's disease. J Oral Microbiol. 2019; 1563405. DOI: 10.1080/20002297.2018.1563405. Summation of 
animal studies supporting the $P$. gingivalis infection link with AD risk factor development.

22. *Rokad F, Moseley R, Hardy RS, Chukkapalli S, Crean S, Kesavalu L, et al. Cerebral oxidative stress and microvasculature defects in TNF- $\alpha$ expressing transgenic and Porphyromonas gingivalis-infected ApoE ${ }^{-/}$mice. J Alzheimers Dis. 2017; 60(2): 35969. DOI: 10.3233/JAD-170304. The hippocampal microvascular structure of $\boldsymbol{P}$. gingivalis-infected $\mathrm{ApoE}^{-/-}$mice possesses elevated oxidative stress levels, resulting in the associated tight junction proteins being susceptible to increased oxidative/proteolytic degradation, leading to hydrolysis of the amyloid precursor protein to generate $A \beta$ in wild type mice infected with $P$. gingivalis.

23. ***Moir RD, Lathe R, Tanzi RE. The antimicrobial protection hypothesis of Alzheimer's disease. Alzheimers Dement. 2018; 14(12): 1602-14. DOI: 10.1016/j.jalz.2018.06.3040. The new Antimicrobial Protection Hypothesis reveals brain microbial burden may directly generate $\beta$-amyloid deposits, inflammation, and $A D$ progression. This study underpins the role of microbes in the pathogenesis of $\mathrm{AD}$.

24. ***Singhrao SK, Chukkapalli S, Poole S, Velsko I, Crean SJ, Kesavalu L. Chronic Porphyromonas gingivalis infection accelerates the occurrence of age-related granules in $\mathrm{ApoE}^{-/-}$mice brains. J Oral Microbiol. 2017; 9(1):1270602. DOI: 10.1080/20002297.2016.1270602. ApoE ${ }^{-/-}$mice showing the earliest inflammationmediated tissue injury, accompanied by cerebral blood-brain barrier breachment.

25. **Bowman GL, Dayon L, Kirkland R, Wojcik J, Peyratout G, Severin IC, et al. Blood-brain barrier breakdown, neuroinflammation, and cognitive decline in older adults. Alzheimers Dement. 2018; 14(12):1640-50. DOI: 10.1016/j.jalz.2018.06.2857. Blood-brain-barrier breakdown is associated with cognitive decline and inflammation in non-demented elders.

26. Hardy J, Selkoe DJ. The amyloid hypothesis of Alzheimer's disease: progress and problems on the road to therapeutics. Science. 2002; 297(5580): 353-6. Erratum in: Science 2002; 297(5590): 2209.

27. **Boche D, Donald J, Love S, Harris S, Neal JW, Holmes C, et al. Reduction of aggregated Tau in neuronal processes but not in the cell bodies after Abeta42 
immunisation in Alzheimer's disease. Acta Neuropathol. 2010; 120(1): 13-20.

Removal of Abeta from the brain via immunisation does not improve memory.

28. *Terry RD, Masliah E, Salmon DP, Butters N, DeTeresa R, Hill R, et al. Physical basis of cognitive alterations in Alzheimer's disease: synapse loss is the major correlate of cognitive impairment. Ann Neurol. 1991; 30(4): 572-80. Origins of the synaptic loss theory to explain cognitive deficit.

29. *Masliah E, Hansen L, Albright T, Mallory M, Terry RD. Immunoelectron microscopic study of synaptic pathology in Alzheimer's disease. Acta Neuropathol. 1991; 81(4): 428-33. Provides evidence to support the synaptic loss theory.

30. **Cline EN, Bicca MA, Viola KL, Klein WL. The Amyloid- $\beta$ Oligomer Hypothesis: Beginning of the third decade. J Alzheimers Dis. 2018; 64(s1): S567-S610. DOI:

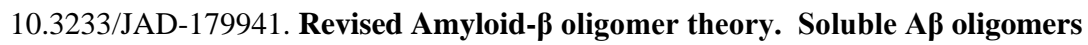
accumulate in an AD-dependent manner in human and animal model brain tissue and, experimentally, to impair learning and memory and instigate major facets of AD neuropathology, including tau pathology, synapse deterioration and loss, inflammation, and oxidative damage.

31. **Olsen I, Singhrao SK. Inflammasome involvement in Alzheimer's disease. J Alzheimers Dis. 2016; 5;54(1): 45-53. This review supports the mechanism of $\boldsymbol{P}$. gingivalis infection promoting cognitive deficit (see ref 52).

32. Gatz M, Mortimer JA, Fratiglioni L, Johansson B, Berg S, Reynolds CA, et al. Potentially modifiable risk factors for dementia in identical twins. Alzheimers Dement. 2006; 2: 110-7.

33. Stein PS, Desrosiers M, Donegan SJ, Yepes JF, Kryscio RJ. Tooth loss, dementia and neuropathology in the Nun study. J Am Dent Assoc. 2007; 138(10): 1314-22; quiz 1381-2.

34. Stein PS, Kryscio RJ, Desrosiers M, Donegan SJ, Gibbs MB. Tooth loss, apolipoprotein E, and decline in delayed word recall. J Dent Res. 2010; 89(5): 473-7. DOI: $10.1177 / 0022034509357881$.

35. Kamer AR, Craig RG, Pirraglia E, Dasanayake AP, Norman RG, Boylan RJ, et al. TNF-alpha and antibodies to periodontal bacteria discriminate between Alzheimer's disease patients and normal subjects. J Neuroimmunol. 2009; 216(1-2): 92-7. DOI: 10.1016/j.jneuroim.2009.08.013. 
36. *Farhad SZ, Amini S, Khalilian A, Barekatain M, Mafi M, Barekatain M, et al. The effect of chronic periodontitis on serum levels of tumor necrosis factor-alpha in Alzheimer disease. Dent Res J (Isfahan). 2014; 11(5): 549-52. Not all of the AD cases they examined at the clinical level co-existed with periodontitis.

37. **Sparks Stein P, Steffen MJ, Smith C, Jicha G, Ebersole JL, Abner E, et al. Serum antibodies to periodontal pathogens are a risk factor for Alzheimer's disease. Alzheimers Dement. 2012; 8(3): 196-203. DOI: 10.1016/j.jalz.2011.04.006. A laboratory study that agreed with the epidemiological study of Chen et al., (ref 38) for the 10 year timeline in risk development following periodontitis diagnosis

38. **Chen CK, Wu YT, Chang YC. Association between chronic periodontitis and the risk of Alzheimer's disease: a retrospective, population-based, matched-cohort study. Alzheimers Res Ther. 2017; 9(1): 56. DOI: 10.1186/s13195-017-0282-6. A 10-year $\mathrm{CP}$ exposure was associated with a 1.707-fold increase in the risk of developing AD.

39. Stewart R, Weyant RJ, Garcia ME, Harris T, Launer LJ, Satterfield S, et al. Adverse oral health and cognitive decline: the health, aging and body composition study. J Am Geriatr Soc. 2013; 61(2): 177-84. DOI: 10.1111/jgs.12094.

40. Kaye EK, Valencia A, Baba N, Spiro A, 3rd, Dietrich T, Garcia RI. Tooth loss and periodontal disease predict poor cognitive function in older men. DOI: 10.1111/j.1532-5415.2010.02788.x.

41. *Daly B, Thompsell A, Sharpling J, Rooney YM, Hillman L, Wanyonyi KL, et al. Evidence summary: the relationship between oral health and dementia. Br Dent J. 2018;223(11): 846-53. DOI: 10.1038/sj.bdj.2017.992. Poor oral hygiene is associated with dementia, and more so amongst people in advanced stages of the disease.

42. *de Souza Rolim T, Fabri GM, Nitrini R, Anghinah R, Teixeira MJ, de Siqueira JT, et al. Oral infections and orofacial pain in Alzheimer's disease: a case-control study. J Alzheimers Dis. 2014; 38(4): 823-9. DOI: 10.3233/JAD-131283. An interventional study on the periodontal treatment in AD patients indicated a plausible causal relationship in demented individuals.

43. *Emanuel R, Sorensen A. A study of oral health prevention behaviours for patients with early stage dementia. Br Dent J. 2018; 224(1): 38-42. DOI:

10.1038/sj.bdj.2018.5. There was clearly scope for improving oral health education and prevention for dementia patients. 
44. *Hajishengallis G. Immune evasion strategies of Porphyromonas gingivalis. J Oral Biosci. 2011; 53(3): 233-40. Exploitation of Toll-like receptor-2, complement receptor 3, C5a anaphylatoxin receptor, and CXC-chemokine receptor 4 by $P$. gingivalis allows the pathogen to escape elimination, obtain nutrients, and collaterally inflict periodontal tissue injury.

45. *Hajishengallis G, Lambris JD. Complement and dysbiosis in periodontal disease. Immunobiology. 2012; 217(11): 1111-6. DOI: 10.1016/j.imbio.2012.07.007. P. gingivalis expresses $\mathrm{C} 5$ convertase-like enzymatic activity and adeptly exploits complement-TLR crosstalk to subvert host defenses and escape elimination.

46. Hajishengallis G, Abe T, Maekawa T, Hajishengallis E, Lambris JD. Role of complement in host-microbe homeostasis of the periodontium. Semin Immunol. 2013; 25(1): 65-72. DOI: 10.1016/j.smim.2013.04.004.

47. Hussain M, Stover CM, Dupont A. P. gingivalis in periodontal disease and atherosclerosis - scenes of action for antimicrobial peptides and complement. Front Immunol. 2015; 6: 45. DOI: 10.3389/fimmu.2015.00045.

48. Olsen I, Hajishengallis G. Major neutrophil functions subverted by Porphyromonas gingivalis. J Oral Microbiol. 2016; 8: 30936. DOI: 10.3402/jom.v8.30936.

49. Olsen I, Singhrao SK, Osmundsen H. Periodontitis, pathogenesis and progression: miRNA-mediated cellular responses to Porphyromonas gingivalis. J Oral Microbiol. 2017; 9(1): 1333396. DOI: 10.1080/20002297.2017.1333396.

50. ***Dominy SS, Lynch C, Ermini F, Benedyk M, Marczyk A, Konradi A, et al. Porphyromonas gingivalis in Alzheimer's disease brains: Evidence for disease causation and treatment with small-molecule inhibitors. Sci. Adv. 2019; 5: eaau3333. This study has provided the strongest evidence for causal links of $\boldsymbol{P}$. gingivalis infection with AD. It has raised the vital awareness in periodontitis and AD developmental links. It offers hope for a future treatment via their gingipain inhibiting drugs

51. **Llorente P, Kristen H, Sastre I, Toledano-Zaragoza A, Aldudo J, Recuero M, et al. A free radical-generating system regulates amyloid oligomers: Involvement of cathepsin B. J Alzheimer's Dis. 2018; 66: 1397-408. DOI 10.3233/JAD-170159. Cathepsin B participates in the changes of amyloid oligomer induced by mild oxidative stress. This supports the oxidative stress related damage following $P$. gingivalis infection as reported in reference 22 . 
52. **Zhang J, Yu C, Zhang X, Chen H, Dong J, Lu W, et al. Porphyromonas gingivalis lipopolysaccharide induces cognitive dysfunction, mediated by neuronal inflammation via activation of the TLR4 signaling pathway in C57BL/6 mice. J Neuroinflammation. 2018; 15(1): 37. DOI: 10.1186/s12974-017-1052-x. Offer a mechanism of how $\boldsymbol{P}$. gingivalis-LPS-induced neuroinflammation plays an important role in cognitive impairment. This reference complements the review by Olsen and Singhrao reference no 31 .

53. Imamura $\mathrm{T}$. The role of gingipains in the pathogenesis of periodontal disease. J Periodontol. 2003; 74(1): 111-8.

54. *Carter CJ, France J, Crean S, et al. The Porphyromonas gingivalis/host interactome shows enrichment in GWASdb genes related to Alzheimer's disease, diabetes and cardiovascular diseases. Front Aging Neurosci. 2017; 9: 408. DOI: 10.3389/fnagi.2017.00408 P . gingivalis intractome supporting AD susceptibility genes or gene expression changes. In particular lists the supporting references for eroding proteins that keep epithelial/endothelial barriers intact.

55. Cunningham C, Wilcockson DC, Campion S, Lunnon K, Perry VH. Central and systemic endotoxin challenges exacerbate the local inflammatory response and increase neuronal death during chronic neurodegeneration. J Neurosci. 2005; 25: 9275-84.

56. Tanaka $S$, Ide $M$, Shibutani $T$, Ohtaki $H$, Numazawa $S$, Shioda $S$, et al. Lipopolysaccharide-induced microglial activation induces learning and memory deficits without neuronal cell death in rats. J Neurosci Res. 2006; 83: 557-66.

57. Chen J, Buchanan JB, Sparkman NL, Godbout JP, Freund GG, Johnson RW. Neuroinflammation and disruption in working memory in aged mice after acute stimulation of the peripheral innate immune system. Brain Behav Immun. 2008; 18: 223-30.

58. *Henry CJ, Huang Y, Wynne AM, Godbout JP. Peripheral lipopolysaccharide (LPS) challenge promotes microglial hyperactivity in aged mice that is associated with exaggerated induction of both pro-inflammatory IL-1beta and anti-inflammatory IL-10 cytokines. Brain Behav Immun. 2009; 23(3): 309-17. Implicates LPS with release of IL$1 \beta$ and intracerebral inflammation

59. *Bellinger FP, Madamba S, Siggins, GR. Interleukin 1 beta inhibits synaptic strength and long-term potentiation in the rat CA1 hippocampus. Brain Res. 1993; 628: 227-34. Implicate IL-1 $\beta$ in cognitive deficit. 
60. Mishra A, Kim HJ, Shin AH, Thayer SA. Synapse loss induced by interleukin-1beta requires pre- and post-synaptic mechanisms. J Neuroimmune Pharmacol. 2012; 7(3): 571-8. DOI: 10.1007/s11481-012-9342-7.

61. Akiyama H, Barger S, Barnum S, Bradt B, Bauer J, Cole GM, et al. Inflammation and Alzheimer's disease. Neurobiol Aging. 2000; 21(3): 383-421.

62. Allen HB. Alzheimer's disease: Assessing the role of spirochetes, biofilms, the immune system, and amyloid- $\beta$ with regard to potential treatment and prevention. J Alzheimers Dis. 2016; 53(4):1271-6. DOI: 10.3233/JAD-160388.

63. Singhrao SK, Neal JW, Rushmere NK, Morgan BP, Gasque P. Spontaneous classical pathway activation and deficiency of membrane regulators render human neurons susceptible to complement lysis. Am J Pathol. 2000; 157(3): 905-18.

64. Wingrove JA, DiScipio RG, Chen Z, Potempa J, Travis J, Hugli TE. Activation of complement components $\mathrm{C} 3$ and $\mathrm{C} 5$ by a cysteine proteinase (gingipain-1) from Porphyromonas (Bacteroides) gingivalis. J Biol Chem. 1992; 267(26): 18902-7.

65. Popadiak K, Potempa J, Riesbeck K, Blom AM. Biphasic effect of gingipains from Porphyromonas gingivalis on the human complement system. J Immunol. 2007; 178(11): 7242-50.

66. Potempa M, Potempa J, Okroj M, Popadiak K, Eick S, Nguyen KA, et al. Binding of complement inhibitor $\mathrm{C} 4 \mathrm{~b}$-binding protein contributes to serum resistance of Porphyromonas gingivalis. J Immunol. 2008; 181(8): 5537-44.

67. Slaney JM, Curtis MA. Mechanisms of evasion of complement by Porphyromonas gingivalis. Front Biosci. 2008; 13: 188-96.

68. Wang M, Krauss JL, Domon H, Hosur KB, Liang S, Magotti P, et al. Microbial hijacking of complement-toll-like receptor crosstalk. Sci Signal. 2010; 3(109): ra11. DOI: 10.1126/scisignal.2000697.

69. *Olsen I, Singhrao SK. Genetic defects, complement and Porphyromonas gingivalis immune subversion in Alzheimer's disease. J Oral Microbiol. 2018; submitted. P. gingivalis is a keystone pathogen for periodontitis and its co-morbidities because of the mastery of this bacterium at subverting selective steps in the immune system for effective dysbiosis, which in turn amplifies altered gene functions in Alzheimer's disease.

70. *Bielecka E, Scavenius C, Kantyka T, Jusko M, Mizgalska D, Szmigielski B, et al. Peptidyl arginine deiminase from Porphyromonas gingivalis abolishes anaphylatoxin C5a activity. J Biol Chem. 2014; 289(47): 32481-7. DOI: 10.1074/jbc.C114.617142. In 
the context of previous studies, which showed crosstalk between C5aR and Tolllike receptors, and enhanced arthritis development in mice infected with PPADexpressing $\boldsymbol{P}$. gingivalis, a crucial role of PPAD in the virulence of $\boldsymbol{P}$. gingivalis was supported.

71. *Liu Y, Wu Z, Nakanishi Y, Ni J, Hayashi Y, Takayama F, et al. Infection of microglia with Porphyromonas gingivalis promotes cell migration and an inflammatory response through the gingipain-mediated activation of protease-activated receptor- 2 in mice. Sci Rep. 2017; 7(1): 11759. DOI: 10.1038/s41598-017-12173-1. The authors provide the first evidence that Rgp and Kgp cooperatively contribute to the $P$. gingivalisinduced cell migration and expression of proinflammatory mediators through the activation of protease-activated receptor 2.

72. Choi JW, Kim SC, Hong SH, Lee HJ. Secretable small RNAs via outer membrane vesicles in periodontal pathogens. J Dent Res. 2017; 96: 458-66. DOI: $10.1177 / 0022034516685071$.

73. *Singhrao SK, Olsen I. Are Porphyromonas gingivalis outer membrane vesicles, microbullets for sporadic Alzheimer's disease manifestation? J Alzheimers Dis Rep. 2018; 1: 1-10. DOI: 10.3233/ADR-180080. Bacterial cultures and established oral biofilms generate vast numbers of microvesicles and $\boldsymbol{P}$. gingivalis outer membrane vesicles encase key virulence factors (LPS, gingipains, capsule, fimbriae) as though they are complete destructive "microbullets" when shed in the host.

74. Schertzer JW, Whiteley M. Microbial communication superhighways. Cell. 2011; 144(4): 469-70. DOI: 10.1016/j.cell.2011.02.001.

75. **Adamowicz K, Wang H, Jotwani R, Zeller I, Potempa J, Scott DA. Inhibition of GSK3 abolishes bacterial-induced periodontal bone loss in mice. Mol Med. 2012; 18: 1190-6. DOI: 10.2119/molmed.2012.00180. This study confirms the relevance of prior in vitro phenomena and establish GSK3 as a novel, efficacious therapeutic preventing periodontal disease progression in a susceptible host.

76. Wang H, Brown J, Martin M. Glycogen synthase kinase 3: a point of convergence for the host inflammatory response. Cytokine. 2011;53: 130-40.

77. Baek H, Ye M, Kang GH, Lee C, Lee G, Choi DB, et al. Neuroprotective effects of $\mathrm{CD} 4^{+} \mathrm{CD} 25^{+} \mathrm{Foxp}^{+}$regulatory $\mathrm{T}$ cells in a $3 \mathrm{xTg}-\mathrm{AD}$ Alzheimer's disease model. Oncotarget. 2016; 7(43): 69347-57. DOI: 10.18632/oncotarget.12469. 
78. Yang J, Wu J, Liu Y, Huang J, Lu Z, Xie L, et al. Porphyromonas gingivalis infection reduces regulatory $\mathrm{T}$ cells in infected atherosclerosis patients. PLoS One. 2014; 9(1): e86599. DOI: 10.1371/journal.pone.0086599.

79. Gonçalves LS, Ferreira SM, Silva A Jr, Villoria GE, Costinha LH, Souto R, et al. Association of T CD4 lymphocyte levels and subgingival microbiota of chronic periodontitis in HIV-infected Brazilians under HAART. Oral Surg Oral Med Oral Pathol Oral Radiol Endod. 2004; 97(2): 196-203.

80. Emery DC, Shoemark DK, Batstone TE, Waterfall CM, Coghill JA, Cerajewska TL, et al. 16S rRNA Next Generation Sequencing analysis shows bacteria in Alzheimer's post-mortem brain. Front Aging Neurosci. 2017; 9: 195. DOI:

10.3389/fnagi.2017.0019.

\section{Figure legends}

Figure 1. Western blot showing CD14 protein on the human neuroblastoma cell line IMR32. a) is an immunoblot of cell lysate prepared from IMR32 neurons following their standard growth culture medium and incubation conditions, no exposure to virulence factors (control) (lane 1), and eIMR32 neurons cultured in their growth medium to which entrel with $\underline{P}$. gingivalis sterile growth medium diluted 1:4 from stockfor $P$. gingivalis was addedeultures (lane 2).; IMR32 neurons in their growth medium plus $P$. gingivalis ATCC $33277^{\mathrm{T}}$ conditioned medium diluted 1:4 from stock (lane 3) with exposure (test) to P. ging alvalis ATCC $33277^{\mp}$ (lane 3) and strain W50 conditioned medium (diluted 1:4 from stock) (lane 4) spent medium (diluted 1:4 from stock)for $24 \mathrm{~h}$. The proteins were separated by SDS-PAGE electrophoresis and electro transferred onto the PVDF (polyvinylidene difluoride) membrane. Following incubation of the membrane overnight with mouse anti-CD14 antibody, clear bands around the $55 \mathrm{kDa}$ molecular weight were seen (in the control lanes 1 and 2, long arrow) indicatesing that the CD14 receptor protein was expressed present on control by these cells. Upon challenge with $P$. gingivalis $33277^{\mathrm{T}}$ the band completely diminished (lane 3, CD14 cleaved from cell membrane). Treatment of the same cells with the W50 strain surprisingly, only partially cleaved CD14 (lane 4) as compared with the control lanes 1 and 2. b) IMR32 cells grown on coverslips were also incubated with the same anti-CD14 antibody. The green colour shows CD14 labelling on the surface membrane of cells confirmingmeaning that the receptor is intact. The 
red colour indicates the nucleus due to propidium iodide uptake from the mounting medium. c) Following exposure to $P$. gingivalis $33277^{\mathrm{T}}$, the cells for $24 \mathrm{~h}$ (as for the blot), the green labelling was missing and correlated with the blot data. d) Exposure to with the blot data.

Figure 1.

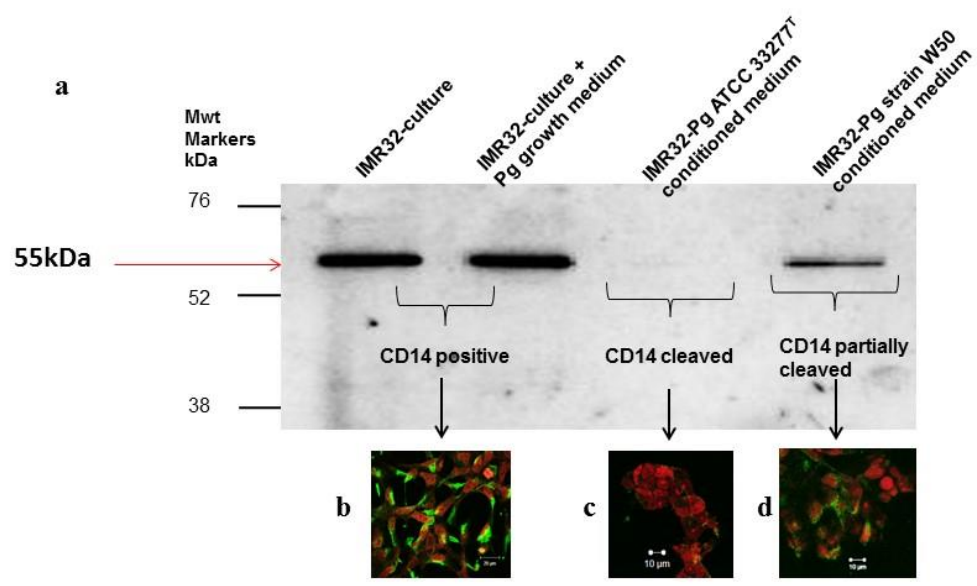

\section{Figure 2}

IMR32 neurons in culture: Fluorescein-phalloidin ( 5 units/ml final, for $30 \mathrm{~min}$ ) labelling for actin cytoskeletal protein (green), (nuclei $=$ red due to propidium iodide uptake). a) IMR32 monolayer in growth medium shows long processes of the cells extending outwards. b) Exposure to $P$. gingivalis ATCC $33277^{\mathrm{T}}$, spent medium (diluted 1:4) for $6 \mathrm{~h}$ demonstrated the processes thickened, whilst the cell soma enlarged. c) As for b, but after $24 \mathrm{~h}$ exposure, the cells rounded up and detached. Images taken after examining the cells under the 510 series Zeiss 
Figure 2.

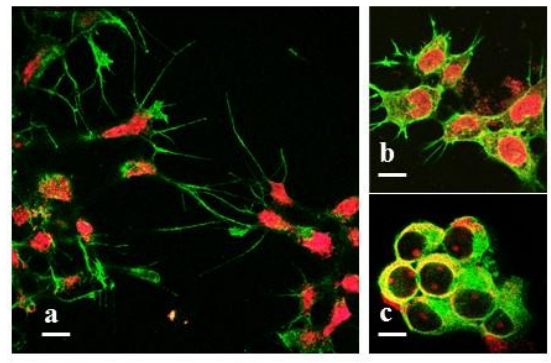

